\title{
LA EXALTACIÓN DE LA SANTA CRUZ DE JUAN NIÑO DE GUEVARA. ANÁLISIS HISTÓRICO-ARTÍSTICO Y PROCESO DE RESTAURACIÓN
}

\author{
ESTRElla Arcos VON HAARTMAN \\ Francisco Capilla LuQue
}

\begin{abstract}
RESUMEN
En este artículo se hace un análisis histórico-artístico de La Exaltación de la Santa Cruz de Juan Niño de Guevara, lienzo que forma parte del programa pictórico de la iglesia de San Julián de Málaga, construida y ornamentada por la Hermandad de la Santa Caridad de Nuestro Señor Jesucristo. Asimismo, se da a conocer el recién concluido proceso de restauración a que ha sido sometida dicha obra.
\end{abstract}

\section{ABSTRACT}

This article presents a historical and artistical analysis of the painting "The Exaltation of the Holy Cross" by Juan Niño de Guevara, which forms part of the pictorical treasures of the church of San Julian (Málaga), erected and ornamented by the Brotherhood of the Holy Charity of Our Lord Jesus Christ. The article also presents the recently concluded restoration of the before mentioned painting.

\section{INTRODUCCIÓN}

La obra realizada por Juan Niño de Guevara (1632-1698) en el último cuarto del siglo XVII para la iglesia del Hospital de San Julián de Málaga, completa el programa iconográfico de las conservadas en la actualidad en este espacio. La importancia de su recuperación estriba, por un lado, en el hecho de ser una pintura que durante mucho tiempo ha estado guardada en condiciones poco adecuadas para su correcta preservación y, por otro, en la posibilidad de profundizar en la técnica de ejecución y el estilo del autor toda vez que no ha sufrido de intervenciones ni modificaciones anteriores que tergiversen el estudio de sus características más singulares. 
Cabe afirmar que en las operaciones de restauración propiamente dichas el criterio estético que prevalecía hasta no hace mucho tiempo ha sido sustituido por el concepto de "restauración crítica" adquiriendo otra dimensión el valor histórico y documental como dualidad en su condición de obra de arte y testimonio de la historia y portador de intrínsecos valores documentales. De ello se deduce que el programa de conservación, junto a los objetivos de tratamiento, es al mismo tiempo una oportunidad única e irrepetible para estudiar la estructura de la obra de arte y aquellos elementos que en gran parte explican su naturaleza, génesis, cronología, etc.

Bajo estos supuestos, la intervención sobre esta obra ha permitido no sólo su puesta en valor, conseguida tanto por la ya citada recuperación de su estructura material y el análisis histórico-artístico, sino también profundizar en la técnica y recursos estilísticos de un autor poco estudiado desde el momento en que se han realizado comparaciones críticas y materiales con las restantes obras de este artista realizadas para el mismo espacio y en la misma época.

La restauración de esta obra, propiedad de la Agrupación de Cofradías, se lleva a cabo gracias a la gestión y el aporte económico de Fundación Málaga. La empresa Quibla Restaura ha sido la encargada de su ejecución, llevándose a cabo a la vista del público con la finalidad de hacerle partícipe y cómplice del gesto restaurador.

\section{LA IGLESIA DE SAN JULIÁN Y SU PROGRAMA PICTÓRICO}

El 13 de mayo de 1682 se fundaba en Málaga la Hermandad de la Santa Caridad de Nuestro Señor Jesucristo, heredera de otra Hermandad de la Caridad más antigua que había casi desaparecido, diezmada tras la epidemia de peste que asolara la ciudad unos años antes ${ }^{1}$. La hermandad, de la que formaba parte la élite de la sociedad malacitana de la época, tenía por objetivo el soco-

1. Para la historia de la hermandad malagueña, véase: CAMINO ROMERO, A.: "Historia de la Hermandad de la Santa Caridad de Málaga", Vía Crucis 10, 1991, 18-23; y "La fundación de la Hermandad de la Santa Caridad de Málaga por el licenciado Alonso García Garcés", Isla de Arriarán X, 1997, 75-87; CAMPOS ROJAS, M. V.: "Breve reseña sobre la Hermandad de la Santa Caridad y del Hospital de San Julián”, Jábega 34, 1981, 57-60; REDER GADOW, M.: "La Hermandad de la Caridad de Málaga y su labor asistencial a los sentenciados a muerte", Actas del II Congreso de Historia de Andalucía, vol. III, Córdoba 1995, 317-30; ZAMORA BERMÚDEZ, M.: "Hospicio de San Julián y funciones de la Hermandad de la Santa Caridad", Estructura benéfico-sanitaria en la Málaga de fines del siglo XVII. Hospitales de San Julián y San Juan de Dios, Málaga 1987, 157 204; y FERNÁNDEZ MÉRIDA, $\mathrm{M}^{\mathrm{a}} \mathrm{D}$.: Los Hospitales malagueños en los siglos XV-XIX. Historia y arquitectura, Málaga 2004. 
rro y enterramiento de los pobres y mendigos, así como atender y dar sepultura a los condenados a muerte, y surgió "como una respuesta de acción social de la clase dominante local ante una coyuntura socioeconómica adversa"2.

El impulsor de esta nueva hermandad sería don Alonso García Garcés, su primer hermano mayor, tesorero del obispo Fray Alonso de Santo Tomás y racionero de la catedral desde 1680. Este clérigo había estado unido por una profunda amistad a don Miguel de Mañara, caballero sevillano que desde 1662 se había entregado a la tarea de renovar la Hermandad de la Caridad hispalense; por ello las relaciones de García Garcés con la Caridad de Sevilla serían tan intensas que ésta llegaría a convertirse en un auténtico modelo a seguir para la hermandad malagueña, hasta el punto de que ésta se declararía hija de aquella en 1683.

Casi de inmediato los hermanos se plantearon la construcción de un hospicio y de una iglesia que serían puestos bajo la advocación de san Julián, y pidieron para ello un solar en la parroquia de los Mártires, donde habían estado las mancebías de la ciudad. En junio de 1683 comenzaron las obras del hospicio que estuvo concluido dos años después, en 1685. A partir de entonces se iniciaron las obras de la iglesia, que se prolongaron por espacio de trece años en los que se produjeron varias interrupciones; el 9 de noviembre de 1698 el templo estaba finalizado ${ }^{3}$. Las trazas y ejecución de la iglesia de San Julián se deben a Miguel Meléndez quien dispuso una planta de cajón de una sola nave cubierta por falsa bóveda de cañón con lunetos, y presbiterio con falsa bóveda de arista. La nave está dividida en tres tramos por pilastras cajeadas y arcos fajones, y en los muros laterales se abren arcos ciegos para altares; asimismo, a los pies de la iglesia se sitúa el coro elevado con balaustrada de perfil cóncavo ${ }^{4}$.

La iglesia sería decorada con un programa pictórico del que se hizo cargo Juan Niño de Guevara (1632-1698), formado por veintinueve lienzos de distintos tamaños y formas ${ }^{5}$. Cuatro de ellos serían colocados en los muros

2. ZAMORA BERMÚDEZ, M.: op.cit., 157 y ss.

3. ÁlVAREZ DE LINERA, J.L.: Crónica de la Hermandad de la Caridad de Nuestro Señor Jesucristo, T. I (1487-1699), ejemplar manuscrito en (A)rchivo (D)iocesano de (M)álaga, leg. 77.

4. La iglesia y hospicio de San Julián en: CAMACHO MARTÍNEZ, R.: Málaga Barroca. Arquitectura religiosa de los siglos XVII y XVIII, Málaga 1981; CAMACHO MARTÍNEZ, R. (Dra.): Inventario artístico de Málaga y su provincia, Madrid 1985; y Guía históricoartística de Málaga, Málaga 1997.

5. Para la vida y obra de Niño de Guevara, así como su obra en San Julián, véase: DÍAZ DE ESCOVAR, N.: "El pintor Niño de Guevara", Curiosidades malagueñas, Málaga 1989; DÍAZ SERRANO, J.: "Un ilustre pintor casi desconocido, D. Juan Niño de Guevara", La Esfera 582, 1925; WETHEY, H.E.: "Juan Niño de Guevara", Anales y Boletín de la 
laterales de la nave e ilustraban distintos momentos de la Vida de San Julián; en los altares abiertos en dichos muros, se disponían: un Crucificado, una Inmaculada y la Aparición de la Virgen a San Julián; la falsa bóveda que cubre la nave se reservó para las alegorías de La Fe, La Esperanza y La Caridad, mientras que el antepecho del coro contaba con nueve lienzos conocidos a través de fotografías anteriores a 1936, en los que se pueden intuir un Buen Pastor y algunas mujeres bíblicas como Judit o María Magdalena ${ }^{6}$. En el presbiterio, casi a modo de tríptico, se encontraban El Triunfo de la Caridad, sobre el altar mayor, coronado por el tondo de La Trinidad, así como La Exaltación de la Santa Cruz, en el lado del Evangelio, y La Invención de la Santa Cruz, en el de la Epístola. Todo el conjunto se completaba con seis lienzos ovales en los que se representaban los apóstoles reunidos por parejas. Tanto las nueve pinturas del coro, como La Invención de la Santa Cruz, La Aparición de la Virgen a San Julián y la Inmaculada, han desaparecido, quedando el programa reducido a las diecisiete obras restantes que se conservan en la actualidad, algunas de las cuales se hallan en una ubicación distinta de la que originalmente tenían.

Se ha querido ver en estas pinturas de Niño de Guevara un programa coherente, como el que realizaron Murillo y Valdés Leal en la iglesia de San Jorge del Hospital de la Caridad de Sevilla, trazado por Miguel de Mañara con el objeto de ensalzar la virtud de la Caridad a través de jeroglíficos, algunos de los cuales constituyen una auténtica ilustración de su obra Discurso de la Verdad $^{7}$. Sin embargo, el programa de la iglesia de San Julián carece de un

Real Academia de Bellas Artes de San Fernando, Madrid 1953, 137-42; LLORDÉN, A.: Pintores y doradores malagueños: ensayo histórico documental (siglos XV-XIX), Ávila 1959; TEMBOURY ÁLVAREZ, J.: "El centenario de Niño de Guevara", Informes históricoartísticos de Málaga, Málaga 1974, 170-3; CLAVIJO GARCÍA, A.: Juan Niño de Guevara y su obra en la Catedral de Málaga, Málaga 1975; "Un pintor del siglo XVII, Juan Niño de Guevara", Jábega 5, 1978, 75-8; Juan Niño de Guevara. Pintor malagueño del siglo XVII, Málaga 1998; CAMINO ROMERO, A. y CABELLO DÍAZ, Ma E.: "Nuevas aportaciones documentales sobre un pintor barroco: Juan Niño de Guevara”, Isla de Arriarán XIV, 1999, $27-48$.

6. Agustín Clavijo opina que en el antepecho del coro estaban representados el Buen Pastor y las alegorías de las virtudes cardinales y teologales. No reconocemos a las citadas virtudes en las fotografías que se conservan; además, éstas son siete, mientras que los lienzos son ocho, más un noveno con el Buen Pastor; por otro lado, la virtudes teologales ya están representadas tanto en el lienzo El Triunfo de la Caridad como en los tres que hay en la bóveda que cubre la nave, por lo que parece excesivo que Niño de Guevara las incluyera de nuevo en esta zona.

7. Véase: GÁLLEGO, J.: Visión y símbolos en la pintura española del Siglo de Oro, Madrid 1996, 168-71, y VALDIVIESO, E. y SERRERA, J.M.: El Hospital de la Caridad de Sevilla, Sevilla 1980. 
motivo que actúe de hilo conductor y son varios los temas y discursos que en él comparten protagonismo. Entre otros están la exaltación de la virtud de la Caridad; la invitación a la práctica de las otras virtudes; la celebración de san Julián, al que la ciudad de Málaga rendía culto desde principios del siglo XVII como abogado de la peste; y el tema de la Santa Cruz, al que hasta ahora no se ha dado la importancia que tiene en todo este conjunto. Casi todos ellos se encuentran reunidos en el gran lienzo que presidía la iglesia, El Triunfo de la Caridad, en el que aparecen La Caridad, acompañada de las otras dos virtudes teologales; san Julián y otros santos bienaventurados; la Trinidad; y la Santa Cruz, triplicada como atributo de $\mathrm{La} \mathrm{Fe}$, como atributo de Jesucristo, y con forma leñosa, portada por un ángel, a la vez como atributo de La Caridad y como símbolo de la Hermandad.

Este tema de la Santa Cruz era muy caro a la Hermandad de la Santa Caridad de Nuestro Señor Jesucristo, pues su propio emblema estaba formado por una cruz leñosa que sobresalía de un corazón llameante, de manera que la Cruz, el instrumento de muerte de Jesucristo, y su símbolo, se identificaba con la misma Hermandad. Tal importancia revestía para los hermanos que Miguel de Mañara terminaría encargando en 1684 a Juan de Valdés Leal un lienzo sobre este asunto para el coro de la iglesia del Hospital de la Caridad, y varios años antes, había escrito en el capítulo XX de la Regla que "la fiesta principal que nuestra Hermandad celebra es la de la Exaltación de la Santa Cruz a 14 de septiembre, la qual (en honra de la Santa Cruz, por quien vino la salud al Mundo, muriendo en ella nuestro Padre Hermano, y Señor, y Dios) se ha de hazer con toda la mayor solemnidad que nos fuere posible" ${ }^{8}$. Ésta es, pues, la óptica desde la que deben verse tanto La Exaltación de la Santa Cruz como La Invención de la Santa Cruz en el programa pictórico de la iglesia de San Julián, colocadas ambas en un lugar principalísimo, a los lados del presbiterio.

\section{EXALTACIÓN DE LA SANTA CRUZ}

En La Exaltación de la Santa Cruz se representa un episodio que tuvo lugar en la primavera del año 630, cuando el emperador Heraclio devolvió a Jerusalén la Santa Cruz, guardada allí desde que santa Elena, madre de Constantino, la descubriese el 14 de septiembre de 326. La Cruz había sido sustraída por el rey de Persia, Coroes II, en el año 614 y enviada a sus dominios junto con el obispo Zacarías, patriarca de la ciudad 9

8. A.D.M. Leg. 74, 3.

9. RUNCIMAN, S.: Historia de las cruzadas, vol. I, Madrid 1973, 25 y ss. 
Tanto este asunto como el de La Invención de la Santa Cruz por santa Elena, y otros relacionados con la leyenda de la Vera Cruz, habían sido ampliamente tratados por la pintura occidental desde la Edad Media, y tanto su difusión como la veneración de las reliquias del lignum crucis, experimentaron un gran desarrollo gracias al impulso de los franciscanos, en especial desde que en el siglo XIII fueran nombrados Custodios de los Santos Lugares. Uno de los ejemplos más importantes lo representan los frescos de La leyenda de la Cruz, pintados por Piero della Francesca en la iglesia de San Francisco de Arezzo entre 1452 y 1459.

La iconografía de las representaciones medievales del tema de La Exaltación de la Santa Cruz sería fijada por Santiago de la Vorágine en la Legenda aurea (ca. 1250). En ella se cuenta que Heraclio, acompañado de su séquito, con gran pompa, llevaba la Cruz a Jerusalén y se disponía a entrar en la ciudad por la Puerta Dorada, cuando ésta se derrumbó, impidiendo el paso del cortejo. En ese momento apareció un ángel recordando al Emperador que Cristo entró por la misma puerta a lomos de una borriquilla, humildemente vestido, por lo que sería indigno que él lo hiciese con tal lujo y boato. Heraclio se desprendió de sus ropas y atributos, y vistió otras más sencillas, instante en el que la puerta se recompuso, permitiéndole el paso. Todavía, uno de los últimos textos hagiográficos medievales, el Catalogus sanctorum et questorum eorum (1493) de Pietro de Natali, recogía esta misma tradición.

Sin embargo, en el siglo XVI, y sobre todo a partir del Concilio de Trento, se impuso un tratamiento algo diferente del tema, despojado de ciertos elementos milagrosos que fueron sustituidos por otros más verosímiles, aunque igualmente extraordinarios. Esta nueva versión sería difundida por los jesuitas, a cuya observancia pertenecían todos los hagiógrafos que la recogieron en sus tratados, como Aloisio Lipómano, que la expone en el tomo V de su De probatis sanctorum historiis (1580), o el cardenal Cesare Baronio en el Martirologyum romanum ad novam kalendarii rationem (1586). En España, Pedro de Ribadeneira en su Flos sanctorum o Libro de las vidas de los Santos (1599), refiere que Heraclio, después de recuperar la Cruz

Entró en la Ciudad con ella, llevándola sobre sus hombros con la mayor pompa y solemnidad que se puede imaginar. Pero sucedió una cosa maravillosa en este triunfo del Emperador, que llegando a la puerta de la Ciudad con la Cruz, paró; y queriendo ir adelante, no pudo moverse, sin poder entender la causa de aquel detenimiento. Iba al lado del Emperador el Patriarca Zacharias, o Modesto (como dice Suidas) y avisole, que por ventura era la causa de aquel milagro tan extraño el llevar la Cruz por aquel camino, por el que Christo, nuestro Salvador, la había llevado, con muy diferente trage, y manera que el señor la llevó: Porque tú, Señor, (dijo el Patriarca) vas vestido y ataviado de riquísimas, e Imperiales 
ropas, y Christo llevaba una vestimenta humilde; tú llevas corona Imperial en la cabeza, y él corona de espinas; y él iba con los pies descalzos, y tú vas con los pies calzados. Pareció a Heraclio, que Zacharías tenía razón; y por lo tanto vistiese un vestido vil, quitose la corona de la cabeza, y con los pies descalzos pudo proseguir con la procesión, hasta poner la Sacrosanta Cruz en el mismo lugar de donde Cosdroas la havía quitado.

Alonso de Villegas la recogió de manera similar en el discurso LI de Fructus sanctorum y Quinta parte del Flos sanctorum (1594); del mismo modo finaliza la última escena de La Exaltación de la Cruz, obra del dramaturgo Pedro Calderón de la Barca publicada en $1652^{10}$.

Esta última versión es la que Niño de Guevara utilizó para su obra $L a$ Exaltación de la Santa Cruz. En el enorme lienzo que, incompleto, mide 2,51 $\mathrm{m} \times 6,17 \mathrm{~m}$, treinta y cuatro figuras participan en la escena, situada por Niño de Guevara en el preciso instante en que Heraclio se dispone a reanudar la marcha, suprimida ya la causa que le impedía proseguir. El centro del cuadro lo ocupa el Emperador, descalzo, vestido con una rústica túnica marrón, bajo la que asoman el peto y los brazales de su armadura; porta la Cruz sobre el hombro y si no fuera por el acero que sobresale de las vestiduras o el detalle de la mano enjoyada con dos anillos, su figura podría llegar a confundirse con la del Señor en una auténtica imitatio Christi. Varios personajes ayudan a Heraclio a soportar el peso del madero: Zacarías, un soldado y dos obispos. En primer término, Zacarías, vestido de pontifical, con mitra y capa pluvial, ceñidos sus hombros por el palio blanco con cruces negras (atributo propio de los arzobispos y patriarcas), comparte protagonismo con el Emperador, ante quien se inclina sujetando un brazo de la Cruz para aliviarle de la pesada carga. Detrás de Heraclio, dos obispos, ambos con mitra, visten sendas casullas con los colores litúrgicos rosa y verde; tanto el que viste de verde como un soldado situado junto a él, adoptan el papel de cireneos. Ignoramos quiénes pudieran ser estos dos obispos, pues ninguna de las fuentes hagiográficas los incluyen en la escena, ni van acompañados de símbolos o atributo que permitan identificarlos, a no ser que el culto Niño de Guevara quisiera con ellos rendir un homenaje a algunos de los que como san Agustín, san Ambrosio o san Epifanio, escribieron en el pasado sobre este acontecimiento.

A los pies de Heraclio un oficial arrodillado sostiene la corona, el cetro y la espada, mientras que otro, que se cubre con casco empenachado y luce banda roja de general sobre el peto y el espaldar, lleva sus botas y la capa púrpura. El caballo blanco del Emperador, enjaezado, es conducido por otro general,

10. CALDERÓN DE LA BARCA, P.: La Exaltación de la Cruz, en Primera parte de comedias escogidas de los mejores ingenios de España, Madrid 1652. 
asimismo con banda roja, y está rodeado por el séquito, formado por piqueros protegidos por armaduras y capascotes que portan símbolos imperiales: un facies ${ }^{11}$, un estandarte rojo con la inscripción S.P.Q.R., y un águila bicéfala. Cierra la parte izquierda del cuadro un soldado que da la espalda al espectador y apoya sobre su hombro una bandera roja que cuelga por su espalda; la figura de un perro introduce una nota realista. Toda esta zona del lienzo, ocupada por soldados, donde el brillo de las armaduras se combina con los ocres de las botas militares y el rojo de los penachos y de los estandartes, se diferencia claramente del resto de la obra, y presumiblemente corrió a cargo de otro pintor que debió de ayudar a Niño de Guevara, pues hay grandes diferencias en la fisonomía de los personajes, la técnica, o el tono de las carnaciones, distintas de las de las demás figuras. De este pintor nada sabemos, pero debemos suponer que procedía de Francia por algunas huellas que ha dejado. Por un lado, los rasgos faciales de los rubios soldados nos recuerdan a los de Bretaña o Normandía, y, por otro, tanto las botas del Emperador como las de uno de los generales de su séquito están provistas de tacones rojos, que en la segunda mitad de siglo XVII Luis XIV había puesto de moda en la Corte de Francia, $y$ eran de usados exclusivamente por la nobleza francesa ${ }^{12}$.

En la parte derecha del cuadro un cuarto obispo contempla el paso del cortejo y lo bendice con una mano, mientras que con la otra sostiene la cruz patriarcal de doble brazo perteneciente a Zacarías; no va vestido de pontifical, como los otros tres, sino con muceta y solideo, vestiduras no litúrgicas de su rango; este rasgo lo diferencia de ellos y nos permite aventurar que se trata de un personaje contemporáneo de Niño de Guevara. Creemos que se trata Bartolomé Espejo y Cisneros, quien tomó posesión de la silla episcopal de Málaga en 1693 e ingresó como hermano en la Hermandad de la Santa Caridad de Nuestro Señor Jesucristo el 10 de julio de $1695^{13}$. Es muy probable que el obispo Espejo fuera el comitente de, al menos, La Exaltación de la Santa Cruz y de su cuadro hermano, La Invención de la Santa Cruz, motivo por el que Niño de Guevara lo incluiría en la obra. El obispo está acompañado por dos sacerdotes y algunos acólitos ataviados con sotanas negras y blancas albas, que forman un cortejo clerical que acompaña a Zacarías, contrapuesto al cortejo militar que sigue al Emperador Heraclio.

A la derecha de los clérigos, algunas mujeres del pueblo - hay una auténtica madonna con el niño en brazos- se arrodillan ante el paso de la Cruz, y

11. Hacha cuyo mango está recubierto por un haz de leños que en la antigua Roma portaban los lictores precediendo a los cónsules y en época imperial al propio Emperador.

12. Esta moda ya la siguen los cortesanos que aparecen en El canciller Séguier de Le Brun (c. 1655). En el siglo XVIII, la costumbre del uso del tacón rojo por la familia real se impuso también en España, importada por Felipe V; sí lo reflejan los retratos de Houasse y Ranc.

13. (A)rchivo (D)íaz de (E)scovar. Caja 110, doc. 28, y A.D.M. Leg. 59. 
entre ellas destaca la noble figura de un hombre arrodillado, de unos sesenta y cinco años, con melena encanecida, que mira fijamente al espectador. Es sin duda un autorretrato de Niño de Guevara que guarda mucho parecido, salvando la diferencia de edad, con otro que realizara unos cuarenta años atrás en el joven que aparece en La fundación de la Orden Tercera de San Francisco. Cierran la escena por este lado un grupo de soldados que custodian la Puerta Dorada, mientras que al fondo del cuadro se recortan unas colinas y las murallas y torres de la ciudad de Jerusalén.

Tanto para esta obra como para las demás que componen el programa pictórico de la iglesia de San Julián se ha venido planteando una cronología algo amplia e imprecisa que abarca el último tercio del siglo XVII o, a lo sumo, el período comprendido entre 1683, año de comienzo de las obras del Hospicio de San Julián, y 1698, en que muere Niño de Guevara. Es cierto que la ausencia de documentación es uno de los principales escollos con que nos encontramos a la hora de abordar éste y otros aspectos relativos al ciclo pictórico de San Julián; no obstante, algunos datos que aportan los escasos documentos que han llegado a nuestros días permiten aventurar algunas hipótesis.

La fuente principal de que disponemos, tanto para el proceso de construcción de la iglesia, como para otros aspectos relacionados con la Hermandad, una vez que desaparecieron los Libros de Cabildos de la misma, es la Crónica de la Hermandad de la Santa Caridad de Nuestro Señor Jesucristo que escribiera su hermano archivero José Luis Álvarez de Linera ${ }^{14}$, que había tenido acceso a la documentación histórica antes de su pérdida. Por ella sabemos que hasta marzo de 1696 la iglesia estaba en construcción - en alberca- y aún no habían llegado las maderas que permitirían techarla. Es impensable que antes de esa fecha estuvieran realizados los grandes cuadros que debían situarse en el presbiterio, así como otros que irían distribuidos por el resto de templo, enmarcados con molduras; por otra parte, los esfuerzos económicos de la Hermandad irían destinados a la conclusión de las obras más que a la decoración. En este sentido, el ingreso como hermano en octubre de 1695 del obispo Espejo fue providencial y debió traer consigo un importante aporte económico; este ingreso tuvo lugar el mismo año en que fue elegido hermano mayor el influyente canónigo de la Catedral, don Juan de Pedregal y Figueroa, otro de los artífices de la iglesia y programa que nos ocupa, que permanecería en el cargo hasta 1721. Unos meses antes, en abril de 1695, Niño de Guevara se había instalado en una casa de la calle Molinillo del Aceite, esquina a calle Carretería, muy cerca de San Julián ${ }^{15}$, y este hecho seguramente guardaría

14. A.D.M. Leg. 77.

15. CLAVIJO GARCÍA, A.: Juan Niño de Guevara, pintor malagueño del siglo XVII, Málaga 1998, 45. 
alguna relación con la enorme tarea que a partir de entonces debía acometer. La conclusión de las obras de la iglesia tuvo lugar en noviembre de 1698 y su consagración solemne en enero de 1699; en agosto de 1698 el hermano mayor hacía constar que faltaba un lienzo de pintura para los altares colaterales ${ }^{16}$, por lo que debemos suponer que el resto de las pinturas estaban acabadas o en proceso de terminación, siendo instaladas en los últimos meses de 1698 (Niño de Guevara fallecería en diciembre de ese año). Por lo tanto, podemos plantear para el programa pictórico de San Julián una cronología más ajustada comprendida entre 1695 y 1698, siendo ejecutado más probablemente a lo largo de los años 1697 y 1698. Desgraciadamente, en la Crónica de Álvarez de Linera faltan los cuadernos correspondientes a esos años, en los que los cabildos de la Hermandad estarían repletos de noticias acerca de las pinturas de Niño de Guevara; precisamente el que no se haga referencia de ellas en los documentos anteriores a diciembre de 1696 indica que aún no se estaban realizando. Este corto periodo de tiempo explicaría la rapidez de ejecución que denotan la mayoría de las pinturas, y el que Niño de Guevara hubiera tenido que recurrir, como denotan algunos lienzos, a diversos ayudantes, e incluso a pintores hoy desconocidos, que le permitieran concluir tan vasta obra en sólo dos años.

Una cuestión que nos parece importante aclarar es el título de la obra que hasta ahora ha sido conocida con el nombre de El Emperador Heraclio viste hábito de penitente. No es éste su título propiamente dicho, sino que le fue impuesto por Agustín Clavijo ${ }^{17}$, basándose en la documentación que se conserva de Narciso Díaz de Escovar. Don Narciso, al escribir sobre las obras de Niño de Guevara afirma que "también hay algunas en San Julián, entre ellas la Invención de la Santa Cruz y el Emperador Heraclio, en hábito de penitente llevando al Calvario el signo glorioso de nuestra Religión[...]"18 o "el Emperador Heraclio en hábito de penitente llevando al Calvario el augusto símbolo de la religión cristiana"19; y su hijo, Joaquín Díaz Serrano, al comentar las obras del presbiterio de San Julián, dice que "en los colaterales [están] la Invención de la Santa Cruz y el Emperador Heraclio en hábito de penitencia, que la lleva al Monte Calvario [...]"20; así mismo la cita Ramón Urbano en su Guía de Málaga de $1898^{21}$. Como puede comprobarse, ni Díaz de Escovar ni su hijo nombran la obra, sino que más bien hacen una descripción corta del asunto que representa. El hijo, también informaba de que en la iglesia de San Felipe se conservaba otro lienzo de Niño de Guevara sobre el mismo asunto, citado, éste sí, con el nom-

16. A.D.E. Caja 110, doc. 28.

17. Véase la bibliografía de dicho autor citada en la nota 5.

18. A.D.E. Caja 176, doc. 2.

19. A.D.E. Caja 176, doc. 6.

20. A.D.E. Caja 176, doc. 4.

21. URBANO, R.: Guía de Málaga, 1898, 137-8. 
bre de La Exaltación de la Cruz ${ }^{22}$. En 1937, el diario Sur se hacía eco de estas pinturas, deterioradas durante los sucesos de 1936 y se refiere a nuestro cuadro con el nombre de El Triunfo de la Santa Cruz ${ }^{23}$. Todas las obras que tratan el tema se conocen con el nombre de La Exaltación de la Santa Cruz, por lo que proponemos adoptarlo definitivamente para este lienzo de Niño de Guevara, convencidos como estamos de que ése debió ser el nombre que le dio su autor.

\section{PROCESO DE RESTAURACIÓN}

La conservación comienza por la valoración de todos los aspectos -formales, estilísticos, funcionales, iconográficos, estructurales, técnicos y materiales- intrínsecos a su carácter específico como bien cultural. Sólo desde su profundo conocimiento y, obviamente, desde la identificación de los daños y alteraciones que presenta, se puede abordar su conservación con unos más amplios objetivos encaminados a la salvaguarda, preservación y puesta en valor del bien patrimonial. Por regla general y hasta no hace mucho tiempo, los estudios realizados se han centrado prioritariamente en los aspectos estilísticos y formales, sin reparar en sus características técnicas, lo que ha limitado la adquisición de un conocimiento integral de la producción artística. Por ello, la colaboración entre restauradores, historiadores del arte y científicos tiene un fruto indudable en la calidad de los resultados.

Las dificultades de la intervención llevada a cabo estaban directamente relacionadas tanto por su nefasto estado de conservación y los materiales de calidad muy irregular empleados por el autor, como por las grandes dimensiones de la obra $(615 \times 251 \mathrm{~cm})$. Por otro lado, la circunstancia de que el equipo restaurador ya había intervenido en los restantes lienzos del mismo autor en la iglesia de San Julián supuso una ayuda inestimable para la elección de los métodos más adecuados en el proceso.

La obra, guardada en las dependencias de la Agrupación de Cofradías de Málaga, se encontraba al menos desde 1970 enrollada en una caja de pequeñas dimensiones con la cara policroma hacia adentro. Esta circunstancia era el origen de los principales daños que presentaba, con abundantes pérdidas en las líneas transversales que se habían producido sumándose, además, a las marcas de la línea longitudinal de una doblez anterior. La pintura presentaba, por tanto, falta de adhesión entre los estratos y una pulverulencia generalizada, así como deformaciones permanentes por la inexistencia de un bastidor adecuado. Del mismo modo, dos fragmentos estaban totalmente separados del

22. A.D.E. Caja 176, doc. 6.

23. Sur, 4 de junlio de 1937, pág. 3. 
conjunto, con los bordes muy deshilachados y con unas pérdidas entre ellos y el resto de la obra entre 3 y 5 centímetros, siendo aquí las lagunas más abundantes que la pintura remanente. Cabe destacar, asimismo, los cortes efectuados en el lateral derecho (donde las figuras y motivos mutilados demuestran que la obra era de dimensiones aún mayores) y el espacio cuadrangular del lado izquierdo también desaparecido. Por otro lado, se ha confirmado la total ausencia de una capa de protección (barniz) que la hubiera preservado de la incidencia de los agentes degradantes externos. En cuanto al soporte, tela de lino de trama muy abierta e irregular, presentaba un alto índice de acidez, abundantes depósitos de suciedad y papeles adheridos, contaminación fúngica y una importante debilidad estructural.

Los análisis químicos de las micromuestras recogidas de diferentes puntos de la obra ofrecen conclusiones que han redundado en el mayor conocimiento del autor, su técnica y los materiales utilizados. Así, se confirma que sólo puntualmente hace uso de veladuras para matizar el color subyacente, prefiriendo la aplicación de una sola capa de color donde mezcla los pigmentos molidos manualmente hasta obtener el tono deseado. Junto con el blanco de plomo, negro de huesos, óxidos de hierro, tierras y sienas, destaca el uso de pigmentos orgánicos (cochinilla e índigo), bermellón, amarillo de estaño y plomo, azul esmalte y verdigrís. Estos dos últimos merecen una consideración especial puesto que son responsables de una parte del aspecto actual de la obra: mientras el primero, utilizado al óleo, se altera agrisándose (como ocurre en el celaje) el segundo, procedente del cobre, tiene la peculiaridad que ennegrece al transformarse en oxicloruro, por lo que paisajes y vestimentas de algunos personajes apenas conservan el tono inicial.

En cuanto a la restauración, el análisis de la información recogida es la que posibilita la formulación de los criterios bajo los cuales se sustenta cada uno de los procesos de intervención. La justificación del tratamiento debe basarse, en gran parte, en la lógica científica, pero también hay que recurrir a la argumentación teórica. Habitualmente el restaurador se ampara en las Cartas Internacionales pero a veces son poco precisas o ambiguas. La Carta italiana del Restauro de 1972, ampliada en 1987, inspirada en las ideas de Brandi, sentó unos claros principios: renuncia a toda intervención creativa o modificación de la integridad de la obra, reconocimiento y diferenciación de añadidos o reintegraciones, mínima intervención, compatibilidad de materiales, reversibilidad de nuevos materiales y documentación de las diferentes fases de intervención. Siguiendo estos principios, las actuaciones realizadas pueden compendiarse en los siguientes procesos:

1) Toma de documentación gráfica y fotográfica, con luz normal, rasante, ultravioleta y macrofotografía, a fin de obtener la mayor información posible de la obra. 
2) Extracción de muestras para su análisis químico, que definen la secuencia estatigráfica del conjunto, incluyendo la composición mineralógica de cada uno de los estratos, el grosor de las capas aplicadas, la mezcla de pigmentos elegida para la obtención del tono deseado, el tamaño del grano y tipo de molienda, la estabilidad de los materiales, así como las características de los depósitos de suciedad añadidos.

3) Protección de la capa pictórica, mediante la aplicación de papel japonés y colas orgánicas con añadido de fungicida.

4) Limpiezas mecánicas del polvo y suciedad depositada en la cara posterior de la obra, mediante brochas y aspiración, eliminación del material añadido y tratamiento antifúngico.

5) Sentado de color con adhesivos orgánicos y aplicación puntual de presión y calor controlados, con espátula eléctrica. Este proceso es imprescindible antes de cualquier otra manipulación sobre la obra a fin de evitar pérdidas puntuales de materia y devolver la fijación entre los estratos.

6) Reentelado. Se elige una tela de lino de trama y grosor similar a la original y como adhesivo gacha italiana con añadido de fungicida y trementina de venecia y melaza para una mayor elasticidad. Esta intervención permite devolver la solidez necesaria al soporte, eliminar las deformaciones y recuperar la flexibilidad del mismo. La tela nueva, sometida a un proceso de "envejecimiento" a fin de que pierda apresto y se minimicen los efectos de tensiones diferenciales entre ambas, se coloca sobre un telar metálico con tensores intermedios para evitar alabeos y recibe una imprimación. El proceso es complicado dadas las dimensiones de la obra y se lleva a cabo extendiendo con ayuda de un rulo la tela original sobre la nueva, interponiendo el adhesivo y aplicando calor y presión moderados.

7) Colocación sobre el bastidor. Se realiza uno de nueva factura y dimensiones adecuadas para las prestaciones que se le exige. Se construye con travesaños y largueros de refuerzo y sustituyendo el clásico sistema de cuñas de atirantado en las esquinas por piezas roscadas metálicas. Recibe un tratamiento preventivo antixilófagos y una protección a base de Paralloid B72 en disolvente aromático.

8) Limpieza de la capa pictórica. Consiste en levantar de la superficie todo cuanto es extraño a la naturaleza de la obra, que ofusca los tonos 
originales e impide la apreciación de detalles y puede resultarle nocivo. Constituye, por tanto, un momento determinante en el proceso conservador. No se trata sólo de eliminar sino de neutralizar las acciones química y físicamente dañinas a la obra y supone la posibilidad de recuperar la imagen en su estado original, sin obviar la importancia y el carácter que la pátina (entendida ésta como el envejecimiento natural de los materiales y documento imprescindible para la comprensión del paso del tiempo) ofrece al aspecto final del conjunto. Como precaución ineludible, es fundamental el aporte científico para valorar los mecanismos de acción de los productos de limpieza escogidos, impidiendo o limitando, de este modo, la posibilidad de efectos negativos.

9) Estucado de lagunas pictóricas. Su papel es importante ya que impide que los materiales de alteración se depositen en las cavidades, evita las escamaciones y restituye la unidad de lectura de la obra. En general deben utilizarse productos que den garantía de estabilidad y características físico-químicas compatibles con el original, que no contraigan bajo factores termohigrométricos y no provoquen tensiones. Se emplea la mezcla de sulfato de cal y cola de conejo con añadido de fungicida de tipo tradicional.

10) Reintegración del color. Tiene como objetivo restituir la lectura unitaria y homogénea de una obra de arte alterada con lagunas y abrasiones. Esta intervención debe realizarse sin modificar el valor que el tiempo ha conferido a la pintura, es decir, la pátina y sin, naturalmente, crear una falsificación: cada operación de restauración debe tener como objetivo exclusivamente la conservación de la obra de arte, manteniendo inalterable la originalidad, el significado, el valor histórico-artístico y documental. Es por ello por lo que la reintegración debe ser siempre diferenciada y distinguible del original.

En el pasado, no teniendo como principio la originalidad, sino especialmente el valor estético de la obra, se procedía recreando arbitrariamente las partes faltantes o incluso corrigiendo según el gusto del momento. Hacia el primer decenio del siglo y sobre todo a partir de la Carta del Restauro de Atenas de 1931, surgió la necesidad de definir la correcta metodología de intervención con pleno respeto a la originalidad de la obra de arte. En base a las disposiciones de esta Carta y las que le siguieron se plasmaron los diferentes tipos de restitución cromática. A partir de la postguerra se adoptó la "restauración arqueológica": una vez realizada la limpieza, la pintura permanece tal cual, con sus abrasiones, lagunas y capas subyacentes a la vista. Se podía operar recuperando 
las lagunas pictóricas con tintas planas (de un tono inferior al original) o rellenando hasta nivelarlo con la superficie original y dándole una tinta neutra. Cada intervención estaba sujeta a variaciones en función de la sensibilidad del restaurador y sigue vigente en la actualidad. Hoy día la reintegración pictórica se realiza normalmente por medio de la "selección" o "abstracción" cromática: la primera se utiliza en lagunas de dimensiones limitadas y solo si los elementos formales que quedan en torno son suficientes para reconstruir el diseño pictórico. La segunda cuando no es posible la relación formal de la laguna con la pintura circundante. En ambos casos la reconstrucción debe diferenciarse del original según los principios propuestos por las Cartas del Restauro. A este efecto, entre los métodos más generalizados en la actualidad sigue estando el tratteggio o regattino y el puntillismo -sistema finalmente escogido en este caso-, válido cuando es factible no caer en la invención. Cuando los datos son insuficientes (como ocurre en las lagunas de grandes dimensiones de los extremos) hay que recurrir a las soluciones neutras, cuya dificultad estriba precisamente en conseguir ese carácter neutro que impida que la laguna siga imponiendo su imagen.

Como medio de reintegración se utiliza la acuarela, que no va a afectar a la estabilidad de los materiales, son muy reversibles y ofrecen un aspecto transparente y sutil.

11) Barnizado de protección. Habitualmente se ha considerado la aplicación de una capa de protección (barniz, resinas sintéticas, gomalaca, ceras, etc.) sobre las obras de arte como un sistema válido e imprescindible para proteger la superficie de pequeñas abrasiones, como filtro hacia causas de alteración externas, como aislante ante nuevas aportaciones (reintegraciones) evitando el contacto directo de los productos añadidos con el original y aumentando, por tanto, los niveles de reversibilidad y ausencia de interacción química de aquellos y, por último, reforzando mediante la saturación óptica del color los aspectos cromáticos que el autor pretendió en su obra, siendo un instrumento importante dentro del repertorio expresivo del artista.

12) Matizado del color. Se utilizan pigmentos puros en polvo mezclados con barniz.

13) Barnizado final, pulverizado, con mezcla de barnices mate y brillante a fin de que la capa protectora sea lo más regular posible y evitando brillos innecesarios. 


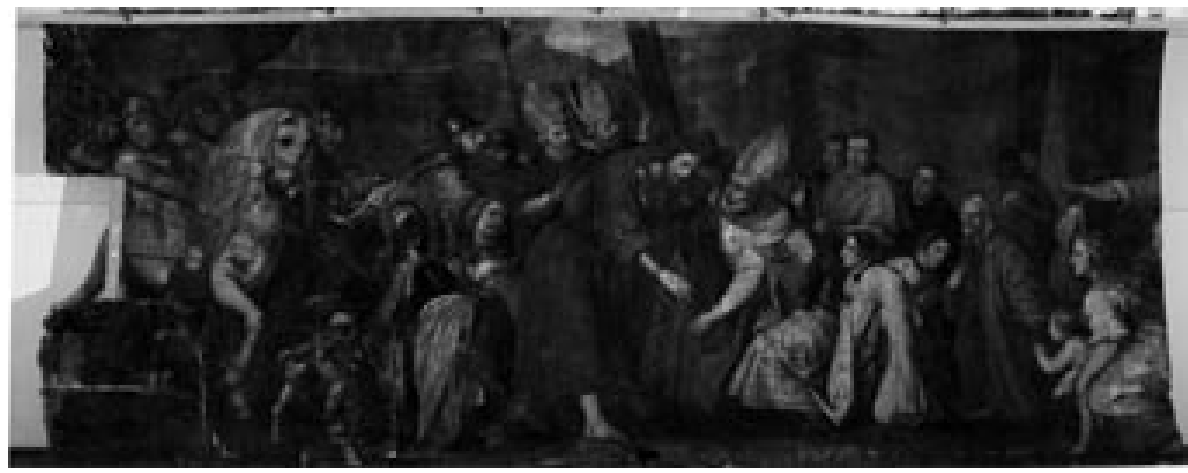

Aspecto general de la obra antes de la intervención

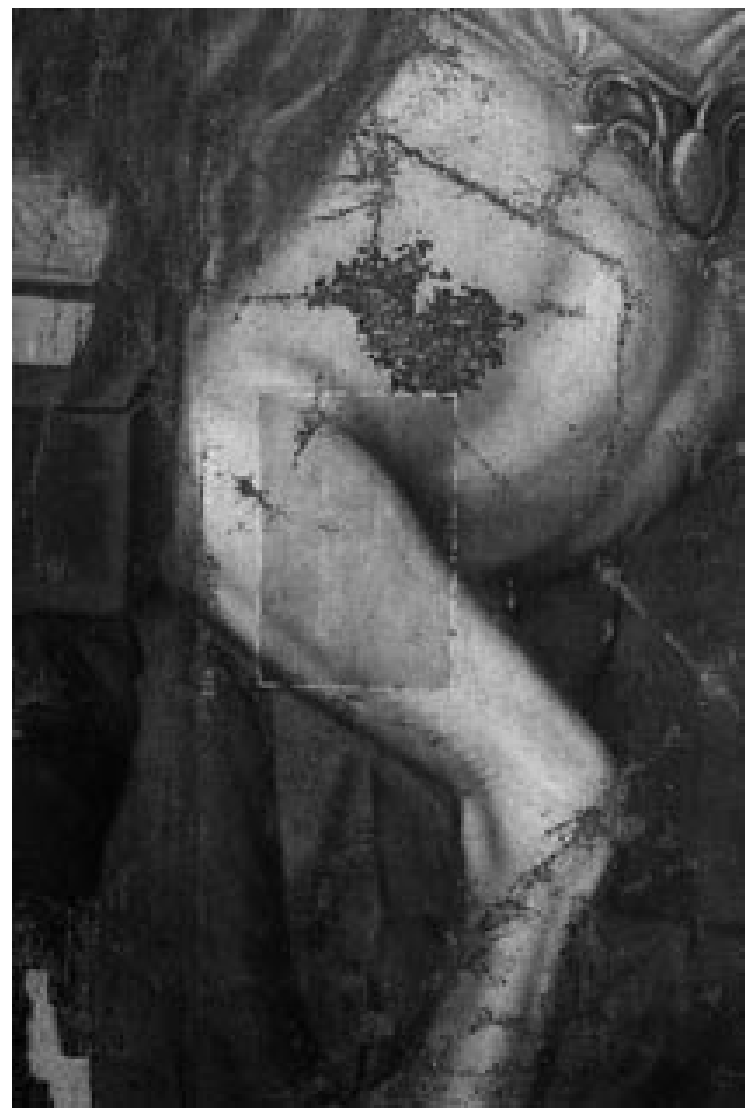

Cata de limpieza de la superficie pictórica 


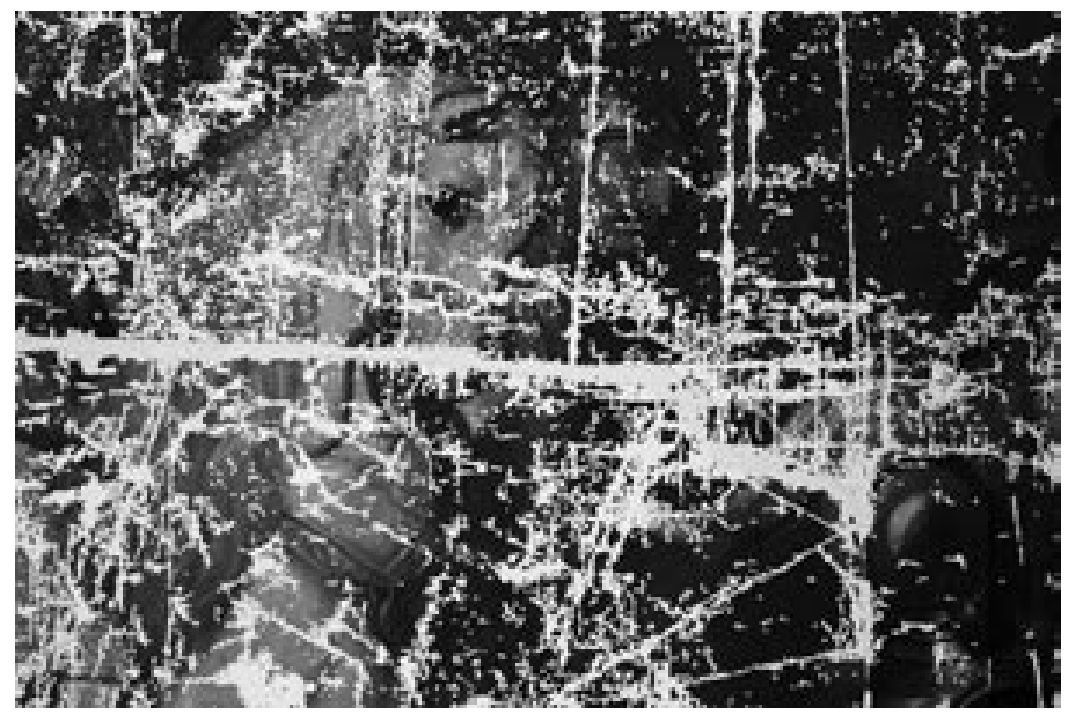

Detalle de la obra durante el proceso de estucado de lagunas

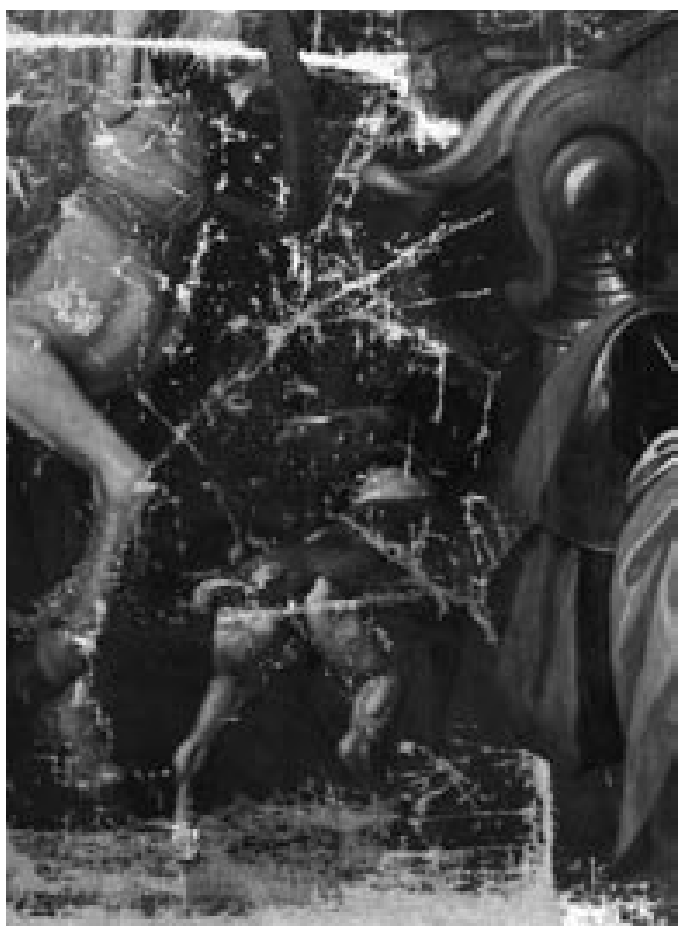

Reintegración del color con técnica del puntillismo y abstracción cromática 


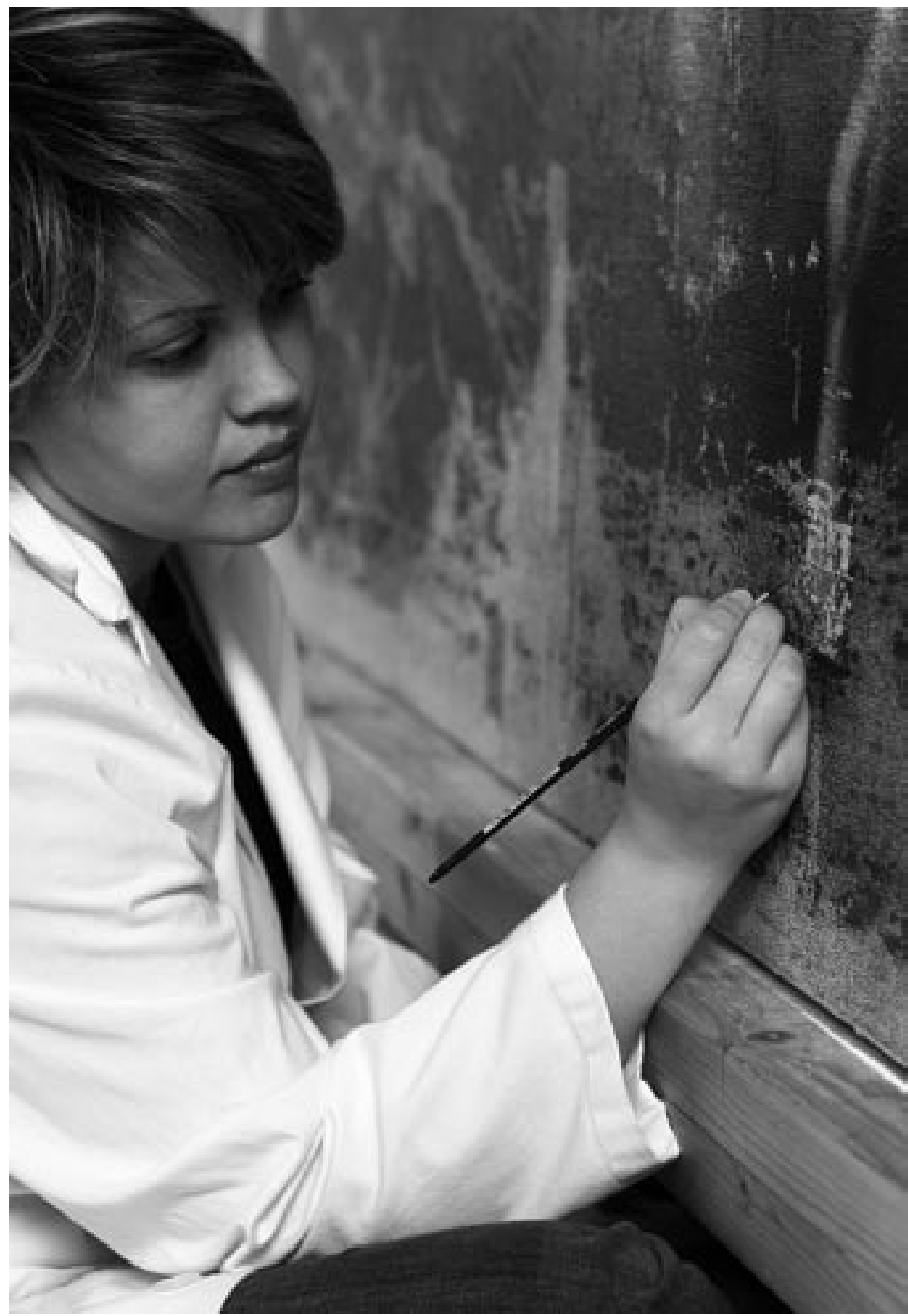

Proceso de reintegración del color 


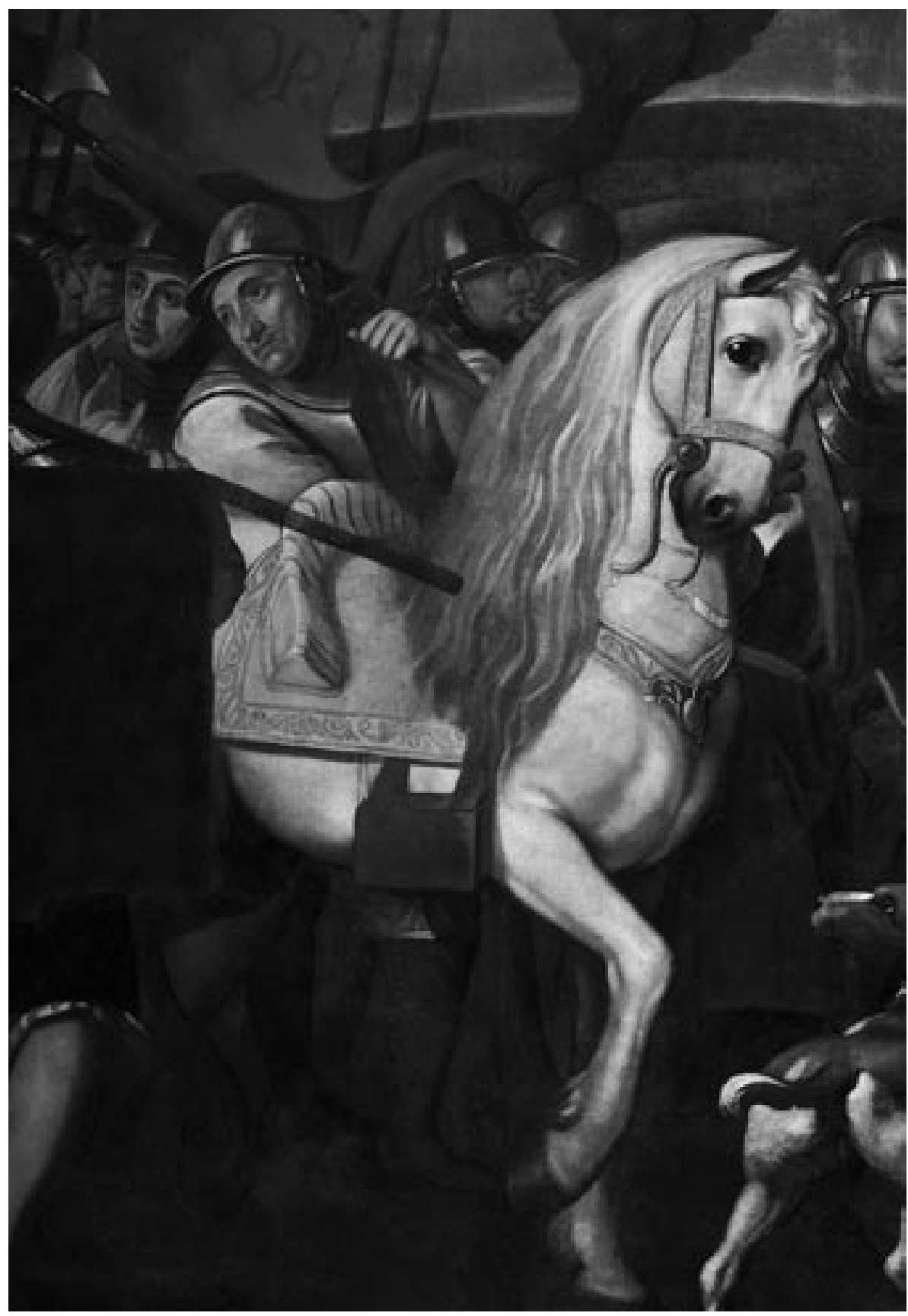

Detalle de la obra una vez finalizada la restauración 


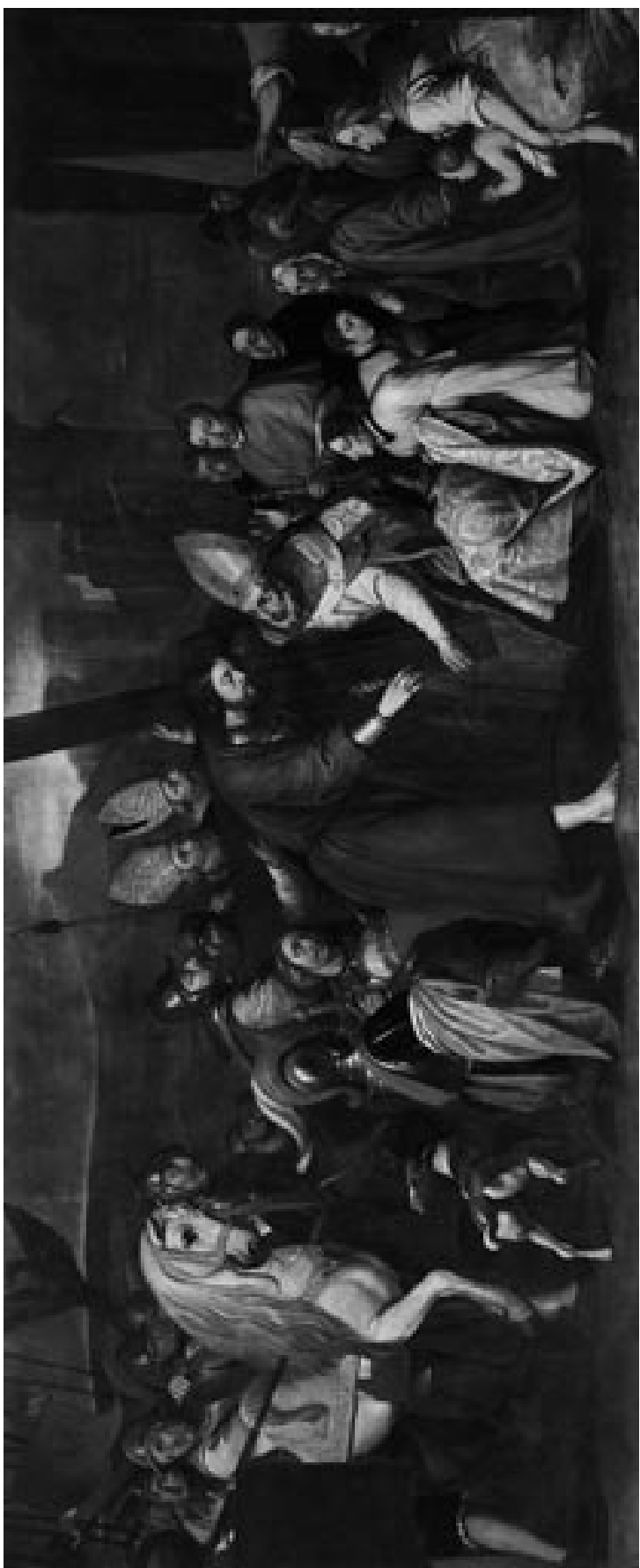

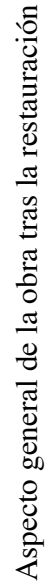

